\title{
Identification of a novel $H R A S$ variant and its association with papillary thyroid carcinoma
}

\author{
RUI DOU ${ }^{1,2}$, LILI ZHANG ${ }^{1}$, TINGXIA LU ${ }^{3}$, DONG LIU $^{1}$, FANG MEI $^{4}$, JIAN HUANG ${ }^{3}$ and LINXUE QIAN ${ }^{1}$ \\ ${ }^{1}$ Department of Ultrasound, Beijing Friendship Hospital, Capital Medical University, Beijing 100050; \\ ${ }^{2}$ Department of Ultrasound, The Second Affiliated Hospital of Inner Mongolia Medical University, Hohhot, \\ Inner Mongolia Autonomous Region 010030; ${ }^{3}$ Experimental Center, Beijing Friendship Hospital, Capital Medical University, \\ Beijing 100050; ${ }^{4}$ Department of Pathology, Peking University Third Hospital, Beijing 100191, P.R. China
}

Received June 12, 2017; Accepted December 11, 2017

DOI: $10.3892 / \mathrm{ol} .2018 .7818$

\begin{abstract}
HRas proto-oncogene (HRAS) is one of the most commonly mutated genes in thyroid cancer, with mutations frequently occurring in the follicular and Hurthle cell subtypes. However, the contribution of mutations in HRAS to papillary thyroid carcinoma (PTC) progression and the tall-cell variant (TCV) is poorly understood. The aim of the present study was to investigate the somatic genetic variants present in HRAS in patients with PTC, and to investigate the association of these mutations with PTC. The present study is a retrospective case-control study using tumor samples collected from 139 patients with PTC and blood samples from 195 healthy individuals. All patient samples were screened for mutations in 'hotspot' regions of HRAS and B-raf proto-oncogene $(B R A F)$ by single-stranded conformational polymorphism analysis, followed by direct sequencing. A novel variant (IVS1-82del getgggcetggg) in the HRAS 5'-untranslated region was identified. There was no difference in age or sex of patients with PTC and the healthy controls; however, the HRAS variant was more frequently detected in PTC tissue than in the healthy control samples ( 37 vs. $26 \%, \mathrm{P}=0.04)$. There was no association between the HRAS variant and age, sex, tumor size, encapsulation, multifocality/intra-thyroidal spread, Tumor-Node-Metastasis stage, history of Hashimoto's disease, $B R A F$ V600E mutation or PTC subtype (all $\mathrm{P}>0.05$ ). There were differences of $B R A F \mathrm{~V} 600 \mathrm{E}$ distribution among different subtypes $\left(\chi^{2}=6.390, \mathrm{P}=0.041\right)$. HRAS variant co-occurring with the BRAF V600E mutation accounted for $31.6 \%$ of the total number $(\mathrm{P}=0.196)$. Therefore, this novel variant of HRAS (IVS1-82del getgggectggg) may be associated with PTC;
\end{abstract}

Correspondence to: Professor Linxue Qian, Department of Ultrasound, Beijing Friendship Hospital, Capital Medical University, 95 Yong an Road, Xicheng, Beijing 100050, P.R. China

E-mail: qianlinxue2002@163.com

Key words: papillary thyroid carcinoma, HRAS proto-oncogene, variants, intron, case-control however, larger scale studies are required to assess the contribution of this novel HRAS variant to PTC progression.

\section{Introduction}

Carcinoma of the thyroid gland is the most common malignant tumor of the endocrine system (1). Papillary thyroid cancer (PTC) is the most common histological type of thyroid cancer, representing $80 \%$ of all cases of thyroid cancer and $85 \%$ of cases of differentiated thyroid cancer $(2,3)$. PTC is 2.9-3.8 times more common in women than in men (4), and is more common in regions associated with a high dietary intake of iodine (5). In the United States, the incidence of PTC is 1.56-3.58/100,000 men and 4.9-10.96/100,000 women (4). PTC is usually associated with a more positive prognosis than follicular thyroid cancer; however, certain subtypes are more aggressive than others (5). Of the PTC subtypes, the tall-cell variant (TCV) is among the most aggressive (6). The 2004 World Health Organization (WHO) classification defined TCV as PTC containing $\geq 50 \%$ tall cells (7). Other characteristics of TCV include an eosinophilic tall cell cytoplasm and nuclear features characteristic of PTC (7). However, the molecular mechanisms that cause TCV differentiation are unclear.

In recent years, B-raf proto-oncogene $(B R A F)$ mutation has been demonstrated to be the most common genetic alteration in PTC (8). It is a molecular marker associated with aggressive tumor behaviors, including size, extra-thyroidal extension, multifocality, lymph node metastasis, tumor recurrence and advanced disease stage $(9,10)$.

The rat sarcoma viral oncogene homolog $(R A S)$ genes, which include the isoforms HRAS, KRAS and NRAS, are crucial effectors in a number of signaling cascades. The mitogen activated protein kinase (MAPK) and the phosphatidylinositol 3-kinase (PI3K) pathways, which mediate cell differentiation, proliferation, and survival, are affected by $R A S$ genes $(11,12)$. RAS activity is regulated by GTP-bound hydrolysis, and any mutation that results in the dysregulation of this hydrolysis results in aberrant MAPK and PI3K/(RAC serine/threonine-protein kinase (Akt) signaling, which are critical events in thyroid carcinogenesis (13).

HRAS is one of the most commonly mutated genes in PTC, particularly in variants identified in follicular (14-17) 
and Hurthle cells (18), reflecting its key regulatory functions. The contribution made by HRAS to PTC progression is poorly understood. Therefore, the present study aimed to investigate the presence of somatic variants in HRAS exhibited by patients with PTC as well as by healthy individuals, and to investigate their association with PTC development. The results of the present study provide an improved understanding of PTC pathogenesis and may provide novel insight for the advancement of PTC treatment.

\section{Materials and methods}

Study design and subjects. The present study involves the retrospective investigation of tumor samples collected from patients with PTC who underwent thyroidectomy at the Beijing Friendship Hospital, Capital Medical University (Beijing, China) between January 2011 and February 2016. A total of 139 PTC patients (106 females and 33 males), age $(48.7 \pm 9.3)$ years old. The final diagnoses were made by pathological examination of the specimens. The following inclusion criteria were applied: i) No treatment for PTC prior to the surgery; ii) the absence of any other type of malignant tumor; iii) tumor size $>0.5 \mathrm{~cm}$; iv) no distant metastasis identified prior to surgery; v) clear results from lymph node dissection; and vi) sufficient DNA extractable from the tissue for analysis.

A total of 195 blood samples from asymptotic people undergoing routine health examinations were acquired as healthy controls. The following exclusion criteria were applied: i) Any symptom of thyroid cancer, and ii) the identification of any biochemical abnormality.

The present study was approved by the Clinical Research Ethics Committee of Beijing Friendship Hospital, Capital Medical University.

Pathological evaluation. Following surgery, formalin-fixed paraffin-embedded (FFPE) tumor-rich tissue areas were dissected from unstained $4-\mu \mathrm{m}$ sections under the guidance of stained slides which was stained by undiluted hematoxylin and eosin (Merck KGaA, Darmstadt, Germany) for $330 \mathrm{sec}$ at room temperature, with the tumor area marked under the guidance of light microscope (original magnification x200). All histological slides were reviewed independently by experienced pathologists specialized in thyroid pathology (from the Peking University Third Hospital, Beijing, China). Diagnoses were performed according to the WHO classification (7). The tumors were classified into histological subtypes: Classic variant of papillary thyroid carcinoma (CVPTC), follicular variant of papillary thyroid carcinoma (FVPTC), and TCV.

DNA extraction. Tumor-rich areas were scraped from the paraffin sections, added to $500 \mu$ l xylene (concentration $\geq 99.0 \%$; Sinopharm Chemical Reagent Co., Ltd., Shanghai, China), and centrifuged $27,400 \mathrm{x} g$ at room temperature for $15 \mathrm{~min}$. The supernatant was discarded and $500 \mu \mathrm{l}$ of anhydrous ethanol was used to disperse the pellet prior to centrifugation twice more $27,400 \mathrm{x} g$ at room temperature for $10 \mathrm{~min}$. The supernatant was discarded and $50 \mu 1$ acetone was used to disperse the pellet prior to further centrifugation $27,400 \mathrm{x} g$ at room temperature for $5 \mathrm{~min}$. Subsequent to air drying, the pellet was suspended in $309 \mu 1$ DNA extraction buffer (300 $\mu$ l digestion buffer and $9 \mu 1$ proteinase K; E.Z.N.A ${ }^{\circledR}$ FFPE DNA Kit; Omega Bio-Tek, Inc., Rockville, MD, USA), and incubated at $55^{\circ} \mathrm{C}$ for 3-5 h. The DNA was extracted from the 195 control samples using Blood DNA kits (Tiangen Biotech Co., Ltd., Beijing, China), according to the manufacturer's instructions. The DNA concentration was determined by spectrophotometric absorption (A) at 230, 260, and $280 \mathrm{~nm}$, and the DNA quality was evaluated by calculating the ratio of optical density (OD) value at 260 and $280 \mathrm{~nm}$ or 260 and $230 \mathrm{~nm}$ measured by a BioSpec-nano spectrophotometer (Shimadzu Corporation, Kyoto, Japan).

Single-stranded conformational polymorphism analysis (SSCP) and direct DNA sequencing for HRAS mutations. SSCP analysis was performed to prescreen for mutations in the HRAS and BRAF exons, in which hotpoint mutations can be identified (19). Primers for SSCP-polymerase chain reaction (PCR) were designed using the Primer 3.0 software (Premier Biosoft International, Palo Alto, CA, USA; Table I. PCR was performed in a total volume of $10 \mu \mathrm{l}$, consisting of $1 \mu 1$ DNA solution $(100 \mathrm{ng} / \mu \mathrm{l}), 0.5$ units of Platinum Taq DNA polymerase (Invitrogen; Thermo Fisher Scientific, Inc., Waltham, MA, USA), $0.1 \mu \mathrm{Ci}\left[\mathrm{a}^{3}{ }^{33} \mathrm{P}\right]$ deoxycytidine triphosphate (ICN Biomedicals, Irvine, CA, USA; specific activity of 3,000 Ci/mmol), 1-4 mmol/1 $\mathrm{MgCl}_{2}, 0.1-0.2 \mathrm{mmol} / 1$ deoxynucleotide triphosphate, $0.2-0.4 \mathrm{mmol} / 1$ each primer, $10 \mathrm{mmol} / \mathrm{l}$ Tris- $\mathrm{HCl}(\mathrm{pH} 8.3)$ and $50 \mathrm{mmol} / \mathrm{l} \mathrm{KCl}$ in a thermal cycler (Biometra GmbH, Göttingen, Germany). The thermocycling conditions were as follows: $95^{\circ} \mathrm{C}$ for $5 \mathrm{~min}, 37-40$ cycles of $95^{\circ} \mathrm{C}$ for $50 \mathrm{sec}, 45-54^{\circ} \mathrm{C}$ for $60 \mathrm{sec}$ and extension $72^{\circ} \mathrm{C}$ for $60 \mathrm{sec}$, and $72^{\circ} \mathrm{C}$ for $5 \mathrm{~min}$. Subsequent to PCR amplification, $10 \mu \mathrm{l}$ PCR product was mixed with $20 \mu \mathrm{l}$ loading buffer (0.02 M NaOH, 95\% formamide, $20 \mathrm{mmol} / 1 \mathrm{EDTA}, 0.05 \%$ xylene cyanol, and $0.05 \%$ bromophenol blue) and denatured at $95^{\circ} \mathrm{C}$ for $10 \mathrm{~min}$, prior to quenching on ice. A total of $5.5 \mu \mathrm{l}$ sample mixture was loaded onto a $12.5 \%$ polyacrylamide non-denaturing gel containing $10 \%$ glycerol. Electrophoresis was performed at $45 \mathrm{~W}$ for 3.5-4.5 h at room temperature with fan cooling. Gels were performed silver staining according to our previous study (20). Samples exhibiting mobility shifts in SSCP analysis were re-amplified using the same primers and PCR conditions as for SSCP analysis and sequenced to determine the HRAS and BRAF genotypes (Beijing Tianyi Huiyuan Co., Ltd., Beijing, China; Table I) (21).

Statistical analysis. $\chi^{2}$ test was used to identify the association between $H R A S$ and $B R A F$ variants, the different subtypes of PTC, and lymph node metastasis. All statistical analyses were performed using SPSS 16.0 (SPSS, Inc., Chicago, IL, USA). $\mathrm{P}<0.05$ was considered to indicate a statistically significant difference.

\section{Results}

Subject characteristics. Table II presents the clinical characteristics of the subjects. There were no differences in age and sex between the 139 patients with PTC and the 195 healthy individuals. However, HRAS variants were more frequent in patients with PTC compared with healthy individuals (37 vs. $26 \%, \mathrm{P}=0.04)$. 
Table I. Primers used for HRAS variant screening in PTC.

\begin{tabular}{llll}
\hline Gene (exon) & Forward sequence, 5'-3' & Reverse sequence, 5'-3' & Product size, bp \\
\hline$H R A S(1)$ & cagtccttgctgctggc & atggttctggatcagctgga & 264 \\
HRAS (2) & cctgtctcctgcttcctctag & tggcaaacacacacaggaag & 298 \\
BRAF (15) & aactcttcataatgcttgctctga & agtaactcagcagcatctcagg & 251 \\
\hline
\end{tabular}

$H R A S$, HRas proto-oncogene; PTC, papillary thyroid carcinoma; $B R A F$, B-raf proto-oncogene.

Table II. Characteristics of the subjects.

\begin{tabular}{lccc}
\hline Variable & $\begin{array}{c}\text { PTC samples, } \\
\mathrm{n}(\%)\end{array}$ & $\begin{array}{c}\text { Control } \\
\text { samples, } \mathrm{n}(\%)\end{array}$ & P-value \\
\hline Total & 139 & 195 & \\
Age, years & & & 0.14 \\
$\leq 45$ & $78(56.1)$ & $126(64.6)$ & \\
$>45$ & $61(44.9)$ & $69(35.4)$ & \\
Sex & & & 0.25 \\
Female & $106(76.3)$ & $136(69.7)$ & \\
Male & $33(23.7)$ & $59(30.3)$ & \\
HRAS variant & $51(36.7)$ & $51(26.2)$ & 0.04 \\
\hline
\end{tabular}

PTC, papillary thyroid carcinoma; HRAS, HRas proto-oncogene.

Molecularanalysis of HRASAndBRAF. A novel variant of HRAS (IVS1-82del gctgggectggg; Fig. 1) was identified to the best of our knowledge for the first time in PTC and adjacent non-tumor tissue: 51/139 (37\%) patients with PTC were heterozygous for the IVS1-82del getgggectggg variant, compared with 51/195 (26\%) healthy controls $(\mathrm{P}=0.04$; Table II). The HRAS variant was not specific to PTC but occurred more frequently in patients with PTC compared with healthy individuals. The frequency of the HRAS variant did not differ among PTC subtypes $(\mathrm{P}=0.95)$. There were no associations between the $H R A S$ variant and age, sex, tumor size, encapsulation, multifocality/intrathyroidal spread, Tumor-Node-Metastasis stage (22), thyroid nodule status, Hashimoto history, BRAF mutation or PTC subtype (all P>0.05; Table III). There were significant differences in the number of $B R A F$ mutations among the different subtypes $(\mathrm{P}=0.041$; Table IV). The presence of the BRAF V600E mutant was not associated with that of the HRAS variant $(\mathrm{P}=0.196$; Table V).

\section{Discussion}

HRAS is one of the most commonly mutated genes in thyroid cancer, particularly the follicular and Hurthle cell subtypes. However, its contribution to PTC and the TCV is poorly understood. Therefore, the present study aimed to investigate the presence of somatic variants in $H R A S$ in patients with PTC and healthy controls, and to investigate their association with PTC development. The results demonstrated that a novel HRAS variant (IVS1-82del gctgggcctggg) could be associated with PTC. Larger studies are required to assess the distribution

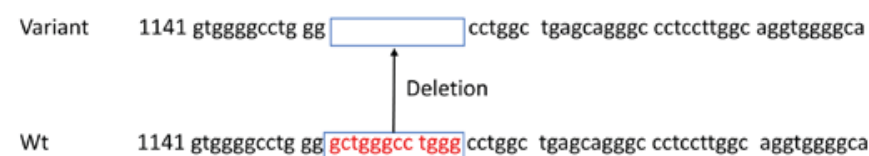

$5^{\prime}-3^{\prime}$

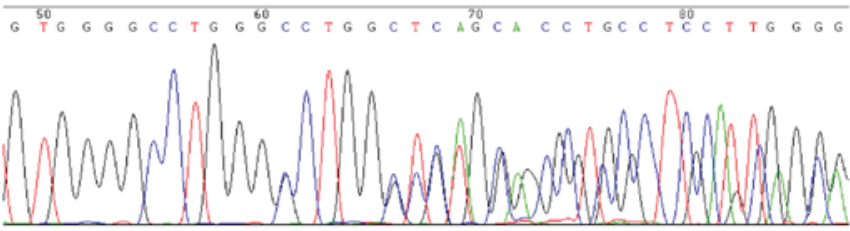

Figure 1. Identification and analysis of a novel HRAS variant in papillary thyroid carcinoma. (A) heterozygous variant with 12 bp deletion in the 5'-untranslated region (IVS1-82del getgggectggg) in the HRAS gene. Wt, wild-type.

of this novel HRAS variant and to validate the results of the present study.

PTC is the most common form of thyroid cancer $(2,3)$. In the present study, the percentage of TCV samples harboring the HRAS variant was $49.6 \%$. The most common etiological factor associated with onset of PTC is radiation; however, other factors, including genetic susceptibility, have been demonstrated to be associated with PTC development (23), as have predispositions such as Hashimoto's thyroiditis (HT) (24). HT has been recognized as a common autoimmune thyroid disorder associated with various antibodies, including thyroid peroxidase antibody (TPOAb) and thyroglobulin antibody (TgAb) (25). If patients present with diffuse goiter (Graves disease), and their TPOAb and TgAb levels are simultaneously increased, an HT diagnosis can be made. However, in the present study, no significant association between HT and the novel $H R A S$ variant was identified.

Mutations associated with phenotypic susceptibility are popular in oncology research; however, such research often requires a large sample size to obtain reliable results. Furthermore, the identification of novel variants often requires DNA sequencing, which is an expensive technology with limited availability in certain countries. The most commonly used method is SSCP $(26,27)$, which is an efficient and sensitive technique used for the identification of single-base mutations.

Mutations in the genes of the RAS family members are known to be associated with thyroid carcinogenesis; RAS mutations have been identified in PTC, follicular 
Table III. Association of HRAS variant, IVS1-82del gctgggcetggg, with clinical features in patients with PTC.

\begin{tabular}{|c|c|c|c|c|}
\hline \multirow[b]{2}{*}{ Variable } & \multirow[b]{2}{*}{ Patients with PTC, n (\%) } & \multicolumn{2}{|c|}{ HRAS status, n (\%) } & \multirow[b]{2}{*}{ P-value } \\
\hline & & Wild-type & Variant & \\
\hline Total & 139 & 88 & 51 & \\
\hline Sex & & & & 0.68 \\
\hline Female & $106(76.3)$ & $66(75.0)$ & $40(78.4)$ & \\
\hline Male & $33(23.7)$ & $22(25.0)$ & $11(21.6)$ & \\
\hline Age, years & & & & 0.11 \\
\hline$\leq 45$ & $78(56.1)$ & $54(31.4)$ & $24(47.1)$ & \\
\hline$>45$ & $61(43.9)$ & $34(68.6)$ & $27(52.9)$ & \\
\hline Tumor size, mm & & & & 0.11 \\
\hline$\leq 10$ & $79(56.8)$ & $55(62.5)$ & $24(47.1)$ & \\
\hline$>10$ & $60(43.2)$ & $33(37.5)$ & $27(52.9)$ & \\
\hline Encapsulation & $54(38.9)$ & $32(63.6)$ & $22(53.1)$ & 0.47 \\
\hline Multifocality/intrathyroidal spread & $32(23.0)$ & $19(21.6)$ & $13(25.5)$ & 0.68 \\
\hline Lymph node metastasis & $66(47.5)$ & $39(44.3)$ & $27(72.7)$ & 0.40 \\
\hline TNM stage & & & & 0.56 \\
\hline $\mathrm{I} / \mathrm{II}$ & $99(71.2)$ & $61(69.3)$ & $38(74.5)$ & \\
\hline III/IV & $40(28.8)$ & $27(30.7)$ & $13(25.5)$ & \\
\hline Hashimoto's disease & $77(55.3)$ & $51(57.9)$ & $26(50.9)$ & 0.49 \\
\hline PTC subtype & & & & 0.95 \\
\hline CVPTC & $34(24.5)$ & $22(25.0)$ & $12(23.5)$ & \\
\hline FVPTC & $36(25.9)$ & $22(25.0)$ & $14(27.5)$ & \\
\hline $\mathrm{TCV}$ & $69(49.6)$ & $44(50.0)$ & $25(49.0)$ & \\
\hline
\end{tabular}

HRAS, HRas proto-oncogene; TNM, Tumor-Node-Metastasis; PTC, papillary thyroid carcinoma; CVPTC, classic variant of papillary thyroid carcinoma; FVPTC, follicular variant of papillary thyroid carcinoma; TCV, tall-cell variant.

Table IV. BRAF V600E mutation occurrence in different subtypes of papillary thyroid carcinoma.

\begin{tabular}{lcrcc}
\hline Subtype & $\begin{array}{c}\text { Mutation, } \\
\mathrm{n}(\%)\end{array}$ & $\begin{array}{c}\text { Wild-type, } \\
\mathrm{n}(\%)\end{array}$ & $\chi^{2}$ & P-value \\
\hline CVPTC & $25(73.5)$ & $9(26.4)$ & & 0.041 \\
FVPTC & $24(66.7)$ & $12(33.3)$ & 6.390 & \\
TCV & $60(86.9)$ & $9(13.0)$ & &
\end{tabular}

$B R A F$, B-raf proto-oncogene; CVPTC, classic variant of papillary thyroid carcinoma; FVPTC, follicular variant of papillary thyroid carcinoma; TCV, tall-cell variant. ${ }^{a} \chi^{2}$ test.

carcinoma, follicular adenoma, and medullary thyroid carcinoma (17,28-32). Previous studies have demonstrated that various types of thyroid carcinoma, particularly FVPTC, harbor somatic mutations in HRAS $(15,16,33)$. The HRAS gene is also often activated in urinary tract tumors (34). The 81T $>C$ polymorphism in the HRAS gene is associated with increased risk of skin (35), oral (36), bladder (37), and gastric (38) cancer. It has been demonstrated that the $81 \mathrm{~T}>\mathrm{C}$ polymorphism, which increases protein expression without changing its function, was associated with aneuploidy in thyroid cancer (39). Previous
Table V. Association between $B R A F$ mutation and the novel $H R A S$ variant.

\begin{tabular}{lccccc}
\hline & $H R A S^{-}, \mathrm{n}$ & HRAS $^{+}, \mathrm{n}$ & Total, $\mathrm{n}$ & $\chi^{2}$ & P-value \\
\hline$B R A F^{-}$ & 20 & 7 & 27 & 1.672 & 0.196 \\
$B R A F^{+}$ & 68 & 44 & 112 & & \\
Total & 88 & 51 & 139 & & \\
\hline
\end{tabular}

$B R A F$, B-raf proto-oncogene; $H R A S$, HRas proto-oncogene; $H R A S$, $H R A S$ wild-type; $B R A F^{-}, B R A F$ wild-type; $H R A S^{+}, H R A S$ variant (IVS1-82del gctgggectggg); $B R A F^{+}, B R A F$ mutation exhibited. ${ }^{a} \chi^{2}$ test.

studies have reported that the frequency of $R A S$ variants was $10-43 \%$ in PCT (40-43).

The BRAF V600E mutation has been demonstrated to be the most common genetic alteration in PTC (8). BRAF is a member of the $R A F$ family and is involved in the MAPK pathway (28). Briefly, the MAPK cascade is initiated upon $R A S$ activation, which recruits $B R A F$ to the plasma membrane. The present study demonstrated that $B R A F$ mutations were more frequent in TCV than in other subtypes, and that the HRAS variant occurred concomitantly with the $B R A F$ mutation in 
$31.6 \%$ of PTC samples $(\mathrm{P}=0.196)$. The concomitant mutations are typically present in the CVPTC and TCV subtypes (29.4 vs. $30.4 \%$ ). This indicates that the concomitant mutations may be associated with aggressive disease behavior and poor prognosis; however, further studies are required to confirm this.

Two different mechanisms may be responsible for the carcinogenic effect of $H R A S$ mutations: Modified protein function or increased protein expression $(43,44-46)$. As RAS proteins are involved in cell differentiation, proliferation, and survival, increased expression or activity of HRAS may enhance these activities, which are associated with carcinogenesis. Indeed, increased $R A S$ activation leads to constitutive activation of the downstream targets of RAS proteins, i.e., the MAPK and PI3K/Akt signaling pathways (13). The novel HRAS variant identified in the present study occurs at the 5 ' end of the sequence, which may affect the selective splicing of HRAS and could be associated with tumor pathogenesis. However, the exact effect of this variant on protein expression remains to be determined.

Concomitant $B R A F$ and RAS mutations may allow simultaneous activation of the MAPK and PI3K/Akt signaling pathways in cancer cells, providing a growth advantage $(47,48)$. Long-term follow-up revealed that patients with concomitant mutations had a poorer response to treatment and reduced disease-free survival times (49), indicating that activation of the two genes may have a synergistic effect on disease progression (50).

One previous study revealed no association between HRAS variants and tumor biology (51), whereas other studies have reported associations between HRAS variants and poorly differentiated tumors $(51,52)$. In the present study, HRAS mutations were demonstrated to be associated with follicular thyroid lesions (32). HRAS has been demonstrated to be frequently mutated in Hurthle cells, which are believed to represent a common metaplastic change in damaged thyroid follicular epithelium (53). Hurthle cells can often develop into Hurthle cell cancer, which is categorized as an oncocytic variant of follicular carcinoma (54). The present study did not include follicular carcinoma or Hurthle cell cancer clinical cases; however, it is possible that the HRAS variant arises from follicular or Hurthle cells in PTCs. In addition, the results of the present study indicated that the novel HRAS variant tends to occur in the TCV. Additional studies are required to fully elucidate the role of the novel HRAS variant in tumor biology.

The present study is limited by the number of patients, retrospective nature, and constrained follow-up information. Furthermore, the potential cellular mechanisms of mutation functions in PTC were not determined. In conclusion, a novel variant of HRAS (IVS1-82del getgggectggg) was associated with PTC. Further studies are required to assess the distribution of this novel HRAS variant and to validate the results of the present study.

\section{Acknowledgements}

The authors would like to thank the team of Professor Jian Huang for providing technical support. This study was supported by a grant from the National Natural Science Foundation of China (grant no. 81541132).

\section{References}

1. Hou P, Bojdani E and Xing M: Induction of thyroid gene expression and radioiodine uptake in thyroid cancer cells by targeting major signaling pathways. J Clin Endocrinol Metab 95: 820-828, 2010.

2. Ron E and Schneider AB: Thyroid Cancer. In: Cancer Epidemiology and Prevention. Schottenfeld D and Fraumeni JF (eds.) Oxford University Press, New York, 2006.

3. Rahbari R, Zhang L and Kebebew E: Thyroid cancer gender disparity. Future Oncol 6: 1771-1779, 2010.

4. Aschebrook-Kilfoy B, Ward MH, Sabra MM and Devesa SS: Thyroid cancer incidence patterns in the United States by histologic type, 1992-2006. Thyroid 21: 125-134, 2011.

5. Schneider DF and Chen H: New developments in the diagnosis and treatment of thyroid cancer. CA Cancer J Clin 63: 374-394, 2013.

6. Ghossein R and Livolsi VA: Papillary thyroid carcinoma tall cell variant. Thyroid 18: 1179-1181, 2008.

7. Livolsi VA, Albores-Saavedra J, Asa SL, Baloch ZW, Sobrinho-Simoes M, Wenig B, DeLellis RA, Cady B, Mazzaferri EL, Hay I, et al: Papillary Carcinoma. In: Pathology and Genetics: Tumours of Endocrine Organs. World Health Organization Classification of Tumours. DeLellis RA, Lloyd RV, Heitz R and Eng C (eds.) IARC Press, Lyon, 2004.

8. Kim KB, Cabanillas ME, Lazar AJ, Williams MD, Sanders DL, Ilagan JL, Nolop K, Lee RJ and Sherman SI: Clinical responses to vemurafenib in patients with metastatic papillary thyroid cancer harboring BRAF (V600E) mutation. Thyroid 23: 1277-1283, 2013.

9. Joo JY, Park JY, Yoon YH, Choi B, Kim JM, Jo YS, Shong M and Koo BS: Prediction of occult central lymph node metastasis in papillary thyroid carcinoma by preoperative BRAF analysis using fine-needle aspiration biopsy: A prospective study. J Clin Endocrinol Metab 97: 3996-4003, 2012.

10. Kurtulmus N, Duren M, Ince U, Cengiz Yakicier M, Peker O, Aydin O, Altiok E, Giray S and Azizlerli H: BRAF (V600E) mutation in Turkish patients with papillary thyroid cancer: Strong correlation with indicators of tumor aggressiveness. Endocrine 42: 404-410, 2012

11. Aksamitiene E, Kiyatkin A and Kholodenko BN: Cross-talk between mitogenic Ras/MAPK and survival PI3K/Akt pathways: A fine balance. Biochem Soc Trans 40: 139-146, 2012.

12. Xing M: Genetic alterations in the phosphatidylinositol-3 kinase/Akt pathway in thyroid cancer. Thyroid 20: 697-706, 2010.

13. Nikiforov YE and Nikiforova MN: Molecular genetics and diagnosis of thyroid cancer. Nat Rev Endocrinol 7: 569-580, 2011

14. Zhu Z, Gandhi M, Nikiforova MN, Fischer AH and Nikiforov YE: Molecular profile and clinical-pathologic features of the follicular mutation of papillary thyroid carcinoma. An unusually high prevalence of ras mutations. Am J Clin Pathol 120: 71-77, 2003.

15. Park JY, Kim WY, Hwang TS, Lee SS, Kim H, Han HS, Lim SD, Kim WS, Yoo YB and Park KS: BRAF and RAS mutations in follicular mutation of papillary thyroid carcinoma. Endocr Pathol 24: 69-76, 2013.

16. Rivera M, Ricarte-Filho J, Knauf J, Shaha A, Tuttle M, Fagin JA and Ghossein RA: Molecular genotyping of papillary thyroid carcinoma follicular mutation according to its histological subtypes (encapsulated vs infiltrative) reveals distinct BRAF and RAS mutation patterns. Mod Pathol 23: 1191-1200, 2010.

17. Adeniran AJ, Zhu Z, Gandhi M, Steward DL, Fidler JP, Giordano TJ, Biddinger PW and Nikiforov YE: Correlation between genetic alterations and microscopic features, clinical manifestations and prognostic characteristics of thyroid papillary carcinomas. Am J Surg Pathol 30: 216-222, 2006.

18. Liu RT, Hou CY, You HL, Huang CC, Hock-Liew, Chou FF, Wang PW and Cheng JT: Selective occurrence of ras mutations in benign and malignant thyroid follicular neoplasms in Taiwan. Thyroid 14: 616-621, 2004.

19. Huang J,Pang J, Watanabe T, Ng HK and OhgakiH: Whole genome amplification for array comparative genomic hybridization using DNA extracted from formalin-fixed, paraffin-embedded histological sections. J Mol Diagn 11: 109-116, 2009.

20. Huang J, Zhao YP, Li Q, ZHANG JX, WANG Y and Zhang B: Association of single nucleotide polymorphisms of NBS1 gene with genetic susceptibility to primary liver cancer in a Chinese Han population. Prog Biochem Biophys 39: 678-686, 2012. 
21. Huang J, Grotzer MA, Watanabe T, Hewer E, Pietsch T, Rutkowski S and Ohgaki H: Mutations in the Nijmegen breakage syndrome gene in medulloblastomas. Clin Cancer Res 14: 4053-4058, 2008.

22. Qing W, Fang WY, Ye L, Shen LY, Zhang XF, Fei XC, Chen X, Wang WQ, Li XY, Xiao JC and Ning G: Density of tumor-associated macrophages correlates with lymph node metastasis in papillary thyroid carcinoma. Thyroid 22: 905-910, 2012.

23. Lloyd RV, Buehler D and Khanafshar E: Papillary thyroid carcinoma mutation. Head Neck Pathol 5: 51-56, 2011.

24. Okayasu I, Fujiwara M, Hara Y, Tanaka Y and Rose NR: Association of chronic lymphocytic thyroiditis and thyroid papillary carcinoma. A study of surgical cases among Japanese and white and African Americans. Cancer 76: 2312-2318, 1995.

25. Hiromatsu Y, Satoh H and Amino N: Hashimoto's thyroiditis: History and future outlook. Hormones (Athens) 12: 12-18, 2013.

26. Long J, Wang Y, Li M, Tong WM, Jia JD and Huang J: Correlation of TP53 mutations with HCV positivity in hepatocarcinogenesis: Identification of a novel TP53 microindel in hepatocellular carcinoma with HCV infection. Oncol Rep 30: 119-124, 2013.

27. Huang MD, Chen XF, Xu G, Wu QQ, Zhang JH, Chen GF, Cai Y and Qi FZ: Genetic variation in the NBS1 gene is associated with hepatic cancer risk in a Chinese population. DNA Cell Biol 31: 678-682, 2012

28. Kimura ET, Nikiforova MN, Zhu Z, Knauf JA, Nikiforov YE and Fagin JA: High prevalence of BRAF mutations in thyroid cancer: Genetic evidence for constitutive activation of the RET/PTC-RAS-BRAF signaling pathway in papillary thyroid carcinoma. Cancer Res 63: 1454-1457, 2003.

29. Soares P, Trovisco V, Rocha AS, Lima J, Castro P, Preto A, Máximo V, Botelho T, Seruca R and Sobrinho-Simões M: BRAF mutations and RET/PTC rearrangements are alternative events in the etiopathogenesis of PTC. Oncogene 22: 4578-4580, 2003.

30. Frattini M, Ferrario C, Bressan P, Balestra D, De Cecco L, Mondellini P, Bongarzone I, Collini P, Gariboldi M,Pilotti S, et al Alternative mutations of BRAF, RET and NTRK1 are associated with similar but distinct gene expression patterns in papillary thyroid cancer. Oncogene 23: 7436-7440, 2004

31. Dockhorn-Dworniczak B, Caspari S, Schroder S, Bocker W and Dworniczak B: Demonstration of activated oncogenes of the ras family in human thyroid tumors using the polymerase chain reaction. Verh Dtsch Ges Pathol 74: 415-418, 1990.

32. Schulten HJ, Al-Maghrabi J, Al-Ghamdi K, Salama S, Al-Muhayawi S, Chaudhary A, Hamour O, Abuzenadah A, Gari M and Al-Qahtani M: Mutational screening of RET, HRAS, KRAS, NRAS, BRAF, AKT1 and CTNNB1 in medullary thyroid carcinoma. Anticancer Res 31: 4179-4183, 2011.

33. Rivera M, Ricarte-Filho J, Tuttle RM, Ganly I, Shaha A, Knauf J, Fagin $\mathrm{J}$ and Ghossein R: Molecular, morphologic and outcome analysis of thyroid carcinomas according to degree of extrathyroid extension. Thyroid 20: 1085-1093,2010.

34. Fujita J, Yoshida O, Yuasa Y, Rhim JS, Hatanaka M and Aaronson SA: Ha-ras oncogenes are activated by somatic alterations in human urinary tract tumours. Nature 309: 464-466, 1984.

35. Kreimer-Erlacher H, Seidl H, Back B, Kerl H and Wolf $P$. High mutation frequency at Ha-ras exons 1-4 in squamous cell carcinomas from PUVA-treated psoriasis patients. Photochem Photobiol 74: 323-330, 2001

36. Sathyan KM, Nalinakumari KR, Abraham T and Kannan S: Influence of single nucleotide polymorphisms in H-Ras and cyclin D1 genes on oral cancer susceptibility. Oral Oncol 42: 607-613, 2006

37. Johne A, Roots I and Brockmoller J: A single nucleotide polymorphism in the human H-ras proto-oncogene determines the risk of urinary bladder cancer. Cancer Epidemiol Biomarkers Prev 12: 68-70, 2003.

38. Zhang Y, Jin M, Liu B, Ma X, Yao K, Li Q and Chen K: Association between H-RAS T81C genetic polymorphism and gastrointestinal cancer risk: A population based case-control study in China. BMC Cancer 8: 256, 2008.
39. Castro P, Soares P, Gusmão L, Seruca R and Sobrinho-Simoes M: H-RAS 81 polymorphism is significantly associated with aneuploidy in follicular tumors of the thyroid. Oncogene 25: 4620-4627, 2006.

40. Esapa CT, Johnson SJ, Kendall-Taylor P, Lennard TW and Harris PE: Prevalence of Ras mutations in thyroid neoplasia. Clin Endocrinol (Oxf) 50: 529-535, 1999.

41. Zhu Z, Gandhi M, Nikiforova MN, Fischer AH and Nikiforov YE: Molecular profile and clinical-pathologic features of the follicular variant of papillary thyroid carcinoma. An unusually high prevalence of ras mutations. Am J Clin Pathol 120: 71-77, 2003.

42. Santarpia L, Myers JN, Sherman SI, Trimarchi F, Clayman GL and El-Naggar AK: Genetic alterations in the RAS/RAF/mitogen-activated protein kinase and phosphatidylinositol 3-kinase/Akt signaling pathways in the follicular variant of papillary thyroid carcinoma. Cancer 116: 2974-2983, 2010.

43. Khan MS, Pandith AA, Ul Hussain M, Iqbal M, Khan NP, Wani KA, Masoodi SR and Mudassar S: Lack of mutational events of RAS genes in sporadic thyroid cancer but high risk associated with HRAS T81C single nucleotide polymorphism (case-control study). Tumour Biol 34: 521-529, 2013.

44. Bos JL: ras oncogenes in human cancer: A review. Cancer Res 49: 4682-4689, 1989.

45. Bos JL: The ras gene family and human carcinogenesis. Mutat Res 195: 255-271, 1988.

46. Hashimoto-Gotoh T, Kikuno R, Takahashi M and Honkawa H: Possible role of the first intron of c-H-ras in gene expression: anti-cancer elements in oncogenes. Anticancer Res 8: 851-859, 1988.

47. Vasko V, Saji M, Hardy E, Kruhlak M, Larin A, Savchenko V, Miyakawa M, Isozaki O, Murakami H, Tsushima T, et al: Akt activation and localisation correlate with tumour invasion and oncogene expression in thyroid cancer. J Med Genet 41: 161-170, 2004.

48. Janku F, Lee JJ, Tsimberidou AM, Hong DS, Naing A, Falchook GS, Fu S, Luthra R, Garrido-Laguna I and Kurzrock R: PIK3CA mutations frequently coexist with RAS and BRAF mutations in patients with advanced cancers. PLoS One 6: e22769, 2011

49. Zou M, Baitei EY, Alzahrani AS, BinHumaid FS, Alkhafaji D, Al-Rijjal RA, Meyer BF and Shi Y: Concomitant RAS, RET/PTC, or BRAF mutations in advanced stage of papillary thyroid carcinoma. Thyroid 24: 1256-1266, 2014.

50. Oliveira C, Velho S, Moutinho C, Ferreira A, Preto A, Domingo E Capelinha AF, Duval A, Hamelin R, Machado JC, et al: KRAS and BRAF oncogenic mutations in MSS colorectal carcinoma progression. Oncogene 26: 158-163, 2007.

51. Suarez HG, du Villard JA, Severino M, Caillou B, Schlumberger M, Tubiana M, Parmentier C and Monier R: Presence of mutations in all three ras genes in human thyroid tumors. Oncogene 5: 565-570, 1990.

52. Pilotti S, Collini P, Mariani L, Placucci M, Bongarzone I, Vigneri P, Cipriani S, Falcetta F, Miceli R, Pierotti MA and Rilke F: Insular carcinoma: A distinct de novo entity among follicular carcinomas of the thyroid gland. Am J Surg Pathol 21: 1466-1473, 1997.

53. Ganly I, Ricarte Filho J, Eng S, Ghossein R, Morris LG, Liang Y, Socci N, Kannan K, Mo Q, Fagin JA and Chan TA: Genomic dissection of Hurthle cell carcinoma reveals a unique class of thyroid malignancy. J Clin Endocrinol Metab 98: E962-E972. 2013.

54. DeLellis RA, Lloyd RV and Heitz PU: World Health Organization Classification of Tumors. Pathology and Genetics: Tumors of Endocrine Organs. IARC Press, Lyon, France pp69-72, 2004. 